\title{
Serum Homocysteine and Reactive Species Levels in Fragility Fractures of the Pelvis
}

\author{
ALEXANDRU FILIP1, OANA VIOLA BADULESCU2*, PAUL DAN SIRBU1*, ELENA COJ OCARU ${ }^{3 *}$, NINA FILIP4, GABRIELA PUHA5, \\ LAURA TRANDAFIR ${ }^{6}$, CRISTINA IANCU ${ }^{7}$, MIOARA FLORENTINA TRANDAFIRESCU ${ }^{3}$, OVIDIU ALEXA $^{1}$ \\ ${ }^{1}$ Grigore T. Popa University of Medicine and Pharmacy, Faculty of Medicine, Department of Orthopedics and Traumatology \\ Surgical Sciences (II), 16 Universitatii Str., 700115, Iasi, Romania \\ ${ }^{2}$ Grigore T. Popa University of Medicine and Pharmacy, Faculty of Medicine, Department of Pathophysiology, Morfo-Functional \\ Sciences (II), 16 Universitatii Str., 700115, lasi, Romania \\ ${ }^{3}$ Grigore T. Popa University of Medicine and Pharmacy, Faculty of Medicine, Department of Morphopatology, Morfo-Functional \\ Sciences (I), 16 Universitatii Str., 700115, Iasi, Romania \\ ${ }^{4}$ Grigore T. Popa University of Medicine and Pharmacy, Faculty Of Medicine, Department of Biochemistry, Morpho-functional \\ Sciences (II), 16 Universitatii Str., 700115, Iasi, Romania \\ ${ }^{5}$ Grigore T. Popa University of Medicine and Pharmacy, Faculty Of Medicine, Department of Internal Medicine, 16 Universitatii \\ Str., 700115, Iasi, Romania \\ ${ }^{6}$ Grigore T. Popa University of Medicine and Pharmacy, Faculty of Medicine, Department of Pediatrics, 16 Universitatii Str., 700115, \\ lasi, Romania \\ ${ }^{7}$ Grigore T. Popa University of Medicine and Pharmacy, Faculty Of Pharmacy, Department of Biochemistry, 16 Universitatii Str., \\ 700115, Iasi, Romania
}

\begin{abstract}
Although there are studies showing the link between homocysteine and bone quality, the relationship remains controversial. The purpose of the study was to investigate homocysteine levels in patients with fragility fractures of the pelvis and their association with serum Total Antioxidant Status. The study included a group of 60 patients, aged >65years, with pelvic fragility fractures and osteoporosis admitted in our trauma department between January 2015 and J anuary 2018 and a control group of 30 patients, aged >65years without fragility fractures or osteoporosis. The total antioxidant status (TAS) and homocysteine (Hcy) concentrations were determined in serum of all the patients. TAS levels had a significantly lower values in the group with pelvic fragility fractures compared with the control group $(p<0.001)$. We noticed a significant higher mean of Hcy levels $(p<0.001)$ in patients with pelvic fragility fractures compared with the control group. As conclusion this study shows that patients with fragility fractures of the pelvis have moderately elevated levels of homocysteine and reduced serum Total Antioxidant Status.
\end{abstract}

Keywords: fragility fracture, homocysteine, osteoporosis, oxidative stress

Osteoporosis and associated fractures are a major public health concern due to morbidity, mortality, loss of function and decrease the quality of life. Osteoporosis is characterized by bone demineralisation and loss of resistance that leads to fractures due to fragility. Although bone tissue contains tree cell types, osteoblasts and osteoclasts are key players in bone remodeling.The result of remodeling depends on their coordinated interaction. In osteoporosis the regulation favors osteoclast activity and bone tissue is lost.

Fragility fractures of the pelvis are the result of a lowenergy impact but they can also occur spontaneously in elderly people with osteoporosis [1]. Most of the basic fragility fractures, occur due to minor trauma, show minimal displacementand does notusually require surgical treatment. Some authors [2] believe that functional treatment consisting of rest, pain relief and physical rehabilitation, has the disadvantage of prolonged immobilization with physical and psychological consequences $[3,4]$. Depending on the personality of the fracture and the patient's comorbidities, fragility fractures can be treated also surgically [5-9].

Homocysteine (Hcy) is a non-proteinogenic amino acid, being synthesized in the body as an intermediate in the metabolism of methionine. The structure of the homocysteine is shown in the figure 1 .

An elevated level of this amino acid in the blood is called hyperhomocysteinaemia (hHCy). Depending on the

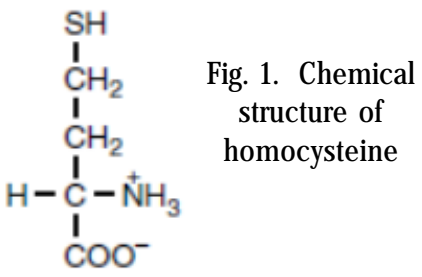

homocysteine levels, three types of $\mathrm{hHCy}$ are distinguished: mild hHCy (16 - $30 \mu \mathrm{mol} / \mathrm{L})$, intermediate hHCy (31 - 100 $\mu \mathrm{mol} / \mathrm{L}$ ) and severe $\mathrm{hHCy}(\mathrm{over} 100 \mu \mathrm{mol} / \mathrm{L}$ ). The common cause of mild hHCy is polymorphism in the methylenetetrahydrofolate reductase gene, manifested particularly as a result of insufficient folic acid intake from food. In addition the homocysteine level increases also as a result of renal failure and smoking. Severe hHCy is determined genetically and it is accompanied by thrombosis of the venous and arterial systems, thromboembolic disease and atherosclerosis complications. The homocysteine level can be usually easily decreased by the administration of vitamins: pyridoxine, B12 and folic acid [10]. Elevated serum levels of homocysteine have deleterious effects on vascular endothelial cells, bone, neural cells [11]. Recent studies indicate that homocysteine is involved in bone matrix degradation and altered biomechanical bone properties through osteoclasts activity [12]. A possible mechanism by which homocysteine is involved in bone 
metabolism is the destruction of the cross-linking of collagen molecules and the increase in the level of advanced endoglicant products. Another mechanism is activation of osteoclastgenesis and causing detrimental effects on bone via oxidative stress induced metalloproteinase-mediated extracellular matrix degradation and decrease in bone blood flow.

The purpose of the study was to investigate homocysteine levels in patients with fragility fractures of the pelvic ring and their association with serum Total Antioxidant Status.

\section{Experimental part}

We enrolled in the present study 60 patients, aged $>65 y e a r s$, with fragility fractures of the pelvic ring admitted in our trauma department between January 2015 and J anuary 2018. We excluded the patients with a history of pelvic fracture and those taking certain anti-osteoporotic drugs. Pelvic fractures that occurred after high energy trauma or on tumorous bone were also excluded.The control group included 30 patients, aged $>65 y$ years, without fragility fractures or osteoporosis. Patients were divided into 2 groups: non-osteoporosis control group (C) had normal bone mineral density (BMD) and osteoporosis patient $(F)$ with fragility fractures of the pelvic ring had low BMD.

\section{Diagnosis of osteoporosis}

Total hip, femoral neck and lumbar spine BMD was measured in all subjects included in the study by dualenergy X-ray absorptiometry (DXA) using the Hologic ${ }^{\circledR D X A}$ scanner and was expressed in absolute values as grams of mineral content per square centimeters of bone area $\left(\mathrm{g} / \mathrm{cm}^{2}\right)$. Coefficients of variation of DXA measurements were $1 \%$. Osteoporosis in post-menopausal women and men over 50 is defined as a T-score less than $2.5 \mathrm{SD}$ (standard deviation minus average density). Reduced bone mass corresponds to the T-score -2.4 to -1.0SD, and normal bone density is defined as the T-score between -1.0 and +1.0 SD [13]. BMD results were classified according to World Health Organization criteria [14].

\section{Determination of TAS}

The serum TAS levels was determined using the TAS Assay Kit from Sigma Aldrich for research and manual use, according to the instructions.

\section{Determination of homocysteine}

Total plasma homocysteine was determined by the immunoassay technique using an Axis Homocysteine EIA kit, according to the instructions.

Informed consent from all patients included in this study was obtained. The current research has been conducted in accordance to the ethical principles set out by the Helsinki Declaration.

\section{Statistical analysis}

Statistical analysis was carried out using SPSS version18. Data were presented as mean \pm standard deviation for normally distributed variables (age, height, weigh).

\section{Results and discussions}

A total of 90 subjects was included in this study. The mean $\pm S D$ age of patients was73 \pm 6.75 years for the $C$ group and $78 \pm 8.35$ years for the $F$ group. General characteristics of the patients included in the study are presented in table 1.

\section{Data given as mean $\pm S D$}

There were no significant differences in age, height, weight, current smoking and coffee consumption between control group and patients with osteoporosis.

World Health Organization defines osteoporosis as a systemic bone disease characterized by a decrease in bone mass and damage to the bone tissue microarchitecture, with a subsequent increase in bone fragility and proneness to fractures [14].

Osteoporosis is a disease of etiology that undergoes the pathogenic pattern of association of several risk factors that do notclinically determine an alarming symptom. Risk factors like gender, ethnicity, physical activity, drinking, smoking, estrogen, $\mathrm{Ca}$ and vitamin $\mathrm{D}$ have a negative impact on bone mineral density and increase the chances of fractures of fragility.

For these risk categories, early identification of osteopenia or osteoporosis is mandatory. The sooner the therapy starts, the lower the risk of fracture. To prevent bone loss some studies support the concept of using nitric oxide donors which can have anti-inflammatory effects $[15,16]$.

The TAS levels varied between $1.111 \mu \mathrm{mol}$ Trolox equivalent $/ L$ and $1.396 \mu \mathrm{mol}$ Trolox equivalent $/ L$ in patients with fragility fracture of the pelvic ring and osteoporosis. In non-osteoporosis control group, TAS values ranged between $1.532 \mu \mathrm{mol}$ Trolox equivalent/L and $1.745 \mu \mathrm{mol}$ Trolox equivalent $/ L$ with a mean of $1.632 \mu$ mol Trolox equivalent/L (table 2 ).

TAS levels had a significantly lower values in the group $F$ compared with the group $C(p<0.001)$.

Oxidative stress is involved in many diseases, disturbing the oxidant-antioxidant balance [17]. Recent studies showed that oxidative stress may cause osteoporosis by involving in bone remodeling [18].Altindag et all. [19] observed that increased osteoclastic activity and decreased osteoblastic activity may be associated with an imbalance between the oxidant and antioxidant status in osteoporosis.

Homocysteine has been suggested to be an oxidizing factor [20,21]. Tyagi $\mathrm{N}$ et al.[22] reported that homocysteine caused the production of reactive oxygen species by autooxidation.

Table 1

BASELINE CHARACTERISTICS OF THE STUDY PARTICIPANTS

\begin{tabular}{|l|l|l|l|}
\hline Characteristic & Control $(\mathrm{n}=30)$ & Osteoporosis $(\mathrm{n}=60)$ & $\mathrm{p}$ \\
\hline Age $($ years $)$ & $73 \pm 6.75$ & $78 \pm 8.35$ & 0.324 \\
\hline Height(cm) & $169 \pm 11.70$ & $167 \pm 12.30$ & 0.124 \\
\hline Weight(kg) & $81 \pm 9.85$ & $85 \pm 11.15$ & 0.431 \\
\hline Current smoking $(\%)$ & 31.21 & 30.10 & 0.612 \\
\hline Coffee consumption $(>3 \mathrm{cups} / \mathrm{d}, \%)$ & 43.51 & 39.14 & 0.321 \\
\hline Femoral neck BMD $\left(\mathrm{g} / \mathrm{cm}^{2}\right)$ & $0.81 \pm 0.03$ & $0.72 \pm 0.04$ & $<0.001$ \\
\hline Lumbar spine BMD $\left(\mathrm{g} / \mathrm{cm}^{2}\right)$ & $1.12 \pm 0.15$ & $0.82 \pm 0.09$ & $<0.001$ \\
\hline Total hip BMD $\left(\mathrm{g} / \mathrm{cm}^{2}\right)$ & $0.96 \pm 0.08$ & $0.81 \pm 0.06$ & $<0.001$ \\
\hline
\end{tabular}

Data given as mean \pm SD 
Table 2

STATISTICAL DESCRIPTION OF TAS VALUES a) $p<0.001 \mathrm{ns)} p>0.05$

\begin{tabular}{|l|l|l|}
\hline Parameter & Group C & Group F \\
\hline Number & 30 & 60 \\
\hline Mean & 1.632 & $1.241^{\text {1) }}$ \\
\hline Standard deviation & 0.086 & 0.062 \\
\hline Variance & 0.051 & 0.032 \\
\hline Skewness Test & -0.024 & 0.018 \\
\hline Std.Error of Skewness & 0.327 & 0.561 \\
\hline Kurtosis & -1.243 & -1.532 \\
\hline Std.Error of Kurtosis & 0.621 & 0.945 \\
\hline Minimum & 1.532 & 1.111 \\
\hline Maximum & 1.745 & 1.396 \\
\hline
\end{tabular}

The Hcy levels varied between $13.215 \mathrm{imol} / \mathrm{l}$ and 16.927 imol// in patients with fragility fracture of the pelvic ring and osteoporosis (F). In non-osteoporosis control group (C) , Hcy values ranged between $10.421 \mathrm{imol} / \mathrm{l}$ and 12.314 imol// with a mean of $11.321 \mathrm{imol} / /$ (table 3).

Plasma Hcy levels are significantly higher in the group $F$ compared with the group $C(p<0.001)$. Similarly, researchers in another study [23] found that Hcy level in elderly patients with osteoporotic fracture is higher than that of non-osteoporotic patients. Numerous studies show that although high levels of homocysteine are a risk factor for fractures, they are not correlated with bone mineral density.

\section{Conclusions}

We show that the osteoporosis patients with fragility fractures of the pelvic ring had reduced TAS compared with control group. As conclusion this study shows that patients with fragility fractures of the pelvis have moderately elevated levels of homocysteine. Further investigations are needed to examine the relationship of oxidative stress and homocysteine in patients with fragility fractures.

\section{References}

1.SOZEN, T., OZISIK, L., BAa ARAN, NÇ., An overview and management of osteoporosis, Eur. J Rheumatol.,4,nr.1, 2017,p.46.

2.SOLES,G.,FERGUSON,T., Fragility fractures of the pelvis, Curr. Rev. Musculoskelet Med.,5,nr.3,2012,p.222.

3.BABAYEV,M.,LACHMANN,E.,NAGLER,W., The controversy surrounding sacral insufficiency fractures: to ambulate or not to ambulate?, Am J. Phys. Med. Rehabil.,79,nr.4,2000, p.404.

4.BADESCU, L; BADULESCU, 0; CIOCOIU, M; BADESCU, M. Modulation of neuropathic pain in experimental diabetes, Journal of Physiology and Biochemistry, 2014, 70(2): 355-361.

5.GHEORGHEVICI,T.S.,VELICEASA, B., PUHA, B.,TOADER,S., ALEXA,I.,D., ALEXA,O., Preoperative Hemoglobin Dynamics in Patients with Trochanteric Fractures A multivariate analysis, Revista de Chimie, 69,nr.11,2018,p. 4220.

6.MAL ANCEA,R.,GAVRILIUC,E.,R.,VELICEASA,B.,PUHA,B., POPESCU,D., ALEXA,O., Methodology of Three-dimensional Printing in Acetabular Fractures, Mat. Plast., 54, no.3, 2017,p.513.
Table 3

STATISTICAL DESCRIPTION OF Hcy VALUES a) $p<0.001 \mathrm{~ns}$ ) $p>0.05$

\begin{tabular}{|l|l|l|}
\hline Parameter & Group C & Group F \\
\hline Number & 30 & 60 \\
\hline Mean & 11.321 & $\left.14.892^{\mathrm{a}}\right)$ \\
\hline Standard deviation & 0.962 & 0.714 \\
\hline Variance & & \\
\hline Skewness Test & 0.095 & 0.052 \\
\hline Std.Error of Skewness & 0.327 & 0.561 \\
\hline Kurtosis & & \\
\hline Std.Error of Kurtosis & 0.733 & 0.872 \\
& & \\
\hline Minimum & 10.421 & 13.215 \\
\hline Maximum & & \\
\hline
\end{tabular}

7.GHEORGHEVICI, T.S., PUHA, B., ALEXA, O., Open radiocarpal dorsal fracture-dislocation associated with chronic distal radioulnar joint dislocation: a case report, Rev Med Chir Soc Med Nat lasi, 121, nr. 1, 2017, p. 143.

8.SIRBU, P. D., TUDOR, R., BEREA, G., SCRIPCARU, A., CIUBARA, B., BADULESCU, O,V., Bipolar Polyethylene Radial Head Artroplasty in Posttraumatic Unstable Elbows. Prosthetic design and clinical results, Mat. Plast., 54, no. 2, 2017, p. 298-301.

9.SIRBU, P.D., TUDOR, R., VERINGA, V., CIUNTU, B.M., RADU, V., CIUBARA, B., BADULESCU, O.V., Strontium Ranelate in the Healing of Fractures Complicated with Delayed Union. It is Really Effective?, Rev. Chim. (Bucharest), 68, no. 8, 2017, p. 1825-1828.

10.RUSU, E., The influence of homocysteine on osteoporosis, R.J .M.M.,120,nr.2,2017,p.22.

11.SAITO, M., MARUMO, K., The Effects of Homocysteine on the Skeleton, Current osteoporosis reports,16,nr.5, 2018,p.554.

12.BEHERA, J., BALA, J., NURU, M., TYAGI, S.C., TYAGI, N., Homocysteine as a pathological biomarker for bone disease,J ournal of cellular physiology,232,nr.10, 2017,p.2704.

13.BINKLEY, N., ADLER, R., BILEZIKIAN, J.P., Osteoporosis diagnosis in men: the T-score controversy revisited, Curr Osteoporos Rep.12,nr.4,2014,p.403.

14.GENANT, H.K., COOPER, C., POOR, G., REID, I., EHRLICH, G., KANIS, J., ET AL., Interim report and recommendations of the World Health Organization task-force for osteoporosis, Osteoporos Int.,10,nr.4,1999,p.259.

15.WIMALAWANSA, S.J ., Nitric oxide and bone, Ann.N. Y. Acad. Sci., 1192,nr.1,2010,p. 391.

16.BUCA, B.R., TARTAU, L.M., REZUS, C., FILIP, C., PINZARIU, A.C., REZUS, E., POPA, G.E., PANAINTE, A., LUPUSORU, C.E., BOGDAN, M., PAVEL, L., The Effects of Two Nitric Oxide Donors in Acute Inflammation in Rats, Rev. Chim. (Bucharest), 69, no.10, 2018, p.2899. 17.SERBAN, R., BADESCU, C., FILIP, A., COBZEANU, M.D., BADESCU, M., BUTNARU, C., HUZUM ,B., FILIP, C., The cat and sod activities in patients with chronic suppurative otitis media, Farmacia,66,nr.6,2018,p.984.

18.ZHOU, Q., ZHU, L., ZHANG, D., LI, N., LI, Q., DAI, P., MAO, Y., LI, X., MA, J., HUANG, S., Oxidative Stress-Related Biomarkers in Postmenopausal Osteoporosis: A Systematic Review and MetaAnalyses, Dis. Markers, 2016. 
19.ALTINDAG, O., EREL, O., SORAN, N.,CELIK ,H., SELEK,S., Total oxidative/anti-oxidative status and relation to bone mineral density in osteoporosis, Rheumatol Int., 28,2008,p. 317.

20.FILIP, C., ALBU, E., LUPASCU, D., FILIP, N., The influence of a new rutin derivative in an experimental model of induced hyperhomocysteinemia in rats, Farmacia, 65, no. 4, 2017, p.596.

21.ALBU, E., LUPASCU, D., FILIP, C., JABA, I., ZAMOSTEANU, N., The influence of a new rutin derivative on homocysteine, cholesterol and total antioxidative status in experimental diabetes in rat, Farmacia, 61,nr.6,2013,p.1167.
22.TYAGI, N., KANDEL, M., MUNJAL, C., QIPSHIDZE, N., VACEK, J.C., PUSHPAKUMAR, S.B., METREVELI, N., TYAGI, S.C., Homocysteine mediated decrease in bone blood flow and remodeling: role of folic acid, J Orthop Res.29,nr.10,2011,p.1511

23.ZHU,Y.,SHEN, J.,CHENG, Q.,FAN,Y., LIN, W., Plasma homocysteine level is a risk factor forosteoporotic fractures in elderly patients, Clin.Interv.Aging,18,nr.11,2016,p.1117.

Manuscript received: 16.06 .2019 